\title{
Genetic polymorphisms in DNA repair and oxidative stress pathways may modify the association between body size and postmenopausal breast cancer
}

\author{
Lauren E. McCullough ${ }^{a}$, Sybil M. Eng ${ }^{b}$, Patrick T. Bradshaw ${ }^{c}$, Rebecca J. Cleveland $^{d}$, \\ Susan E. Steck ${ }^{\mathrm{e}}$, Mary Beth Terry ${ }^{\mathrm{b}}$, Jing Shen ${ }^{\mathrm{f}}$, Katherine D. Crew ${ }^{\mathrm{b}, \mathrm{g}}$, Pavel Rossner Jr. ${ }^{\mathrm{h}}$, \\ Jiyoung Ahn', Christine B. Ambrosonej, Susan L. Teitelbaum ${ }^{k}$, Alfred I. Neugut ${ }^{b, g}$, Regina \\ M. Santella ${ }^{\dagger}$, and Marilie D. Gammon ${ }^{a}$ \\ aDepartment of Epidemiology, University of North Carolina, Chapel Hill, NC, 27599 USA \\ bDepartment of Epidemiology, Columbia University, New York, NY, 10027 USA \\ 'Department of Nutrition, University of North Carolina, Chapel Hill, NC, 27599 USA \\ dDepartment of Medicine, University of North Carolina, Chapel Hill, NC, 27599 USA \\ eDepartment of Epidemiology and Biostatistics, University of South Carolina, Columbia, SC, \\ 29208 USA \\ fDepartment of Environmental Health Sciences, Columbia University, New York, NY, 10027 USA \\ 9Department of Medicine, Columbia University, New York, NY, 10027 USA \\ hLaboratory of Genetic Ecotoxicology, Institute of Experimental Medicine ASCR, Prague, Czech \\ Republic \\ 'Department of Population Health, New York University School of Medicine, New York, NY, 10016 \\ jDivision of Cancer Prevention and Population Sciences, Roswell Park Cancer Institute, Buffalo, \\ NY, 14263 USA
}

kDepartment of Preventive Medicine, Ichan School of Medicine at Mt. Sinai, New York, NY, 10029 USA

\begin{abstract}
Purpose-Obesity is associated with increased bioavailability of estrogen, hyperinsulemia and chronic inflammation, all of which may promote tumor growth. Given DNA repair and oxidative stress pathways may work together with these mechanisms to influence carcinogenesis, we
\end{abstract}

\footnotetext{
(C) 2015 Published by Elsevier Inc.

Corresponding Author: Lauren E. McCullough, Department of Epidemiology, CB \#7435, McGavran-Greenberg Hall, University of North Carolina, Chapel Hill, NC 27599-7435, USA. Phone: +1 (919) 966-7421. Fax: (919) 966-2089. lauren.mccullough@unc.edu. Conflict of Interest: The authors declare that they have no conflict of interest.

Publisher's Disclaimer: This is a PDF file of an unedited manuscript that has been accepted for publication. As a service to our customers we are providing this early version of the manuscript. The manuscript will undergo copyediting, typesetting, and review of the resulting proof before it is published in its final citable form. Please note that during the production process errors may be discovered which could affect the content, and all legal disclaimers that apply to the journal pertain.
} 
hypothesized that genetic variation in these pathways may modify the obesity-postmenopausal breast cancer association.

Methods-Resources from a population-based case-control study (990 cases/970 controls) were used to construct logistic regression models. Body mass index (BMI, weight $\mathrm{kg} / \mathrm{height} \mathrm{m}^{2}$ ) was assessed 1-year prior to reference date. We characterized interactions between BMI and 29 genetic polymorphisms in oxidative stress and DNA repair pathways.

Results-Age-adjusted odds ratios (95\% confidence intervals) for postmenopausal breast cancer were $1.24(1.00-1.52)$ and $1.35(1.09-1.71)$ for $25 \gg \mathrm{BMI}<30$ and BMI $\_30$, respectively. We observed multiplicative interactions ( $\mathrm{p} \unlhd 0.05$ ) for eight gene polymorphisms in DNA repair and oxidative stress pathways. For example, among $M P O$ variant allele carriers, obesity was associated with a two-fold increased risk of postmenopausal breast cancer [2.13 (1.35-3.36)]; however in wild-type homozygotes, the relationship was less pronounced [1.33 (0.93-1.89)]. Our findings were no longer significant after Bonferroni correction.

Conclusions-Obesity may be particularly deleterious for postmenopausal breast cancer development in the presence of biologically plausible DNA repair or oxidative stress genotypes.

\section{Keywords}

breast cancer; body mass index; oxidative stress; DNA repair; epidemiology

\section{Introduction}

Obesity is a major public health problem and is a risk factor for several chronic disorders including heart disease, type 2 diabetes, and certain cancers [1]. The National Center for Health Statistics reports that approximately $35.8 \%$ of the US adult female population is obese [2]. Given the growing prevalence of obesity and its strong links to postmenopausal breast cancer (BC), it is critical to understand the mechanisms driving the association. Several factors produced by adipose tissue are thought to both directly and indirectly promote tumor growth. Increased bioavailability of estrogens resulting from the conversion of androgens to estradiol in peripheral adipose tissue, systemic reductions in sex hormonebinding globin (SHBG), and obesity related hyperinsulemia have been hypothesized as central contributors [3, 4]. Obesity mediated inflammation may also be an important biologic process in the link between obesity and postmenopausal BC. Adipose tissue is known to produce inflammatory cytokines and prostaglandins, leading to localized inflammation [5]. Chronic inflammation can promote changes in the cellular microenvironment causing increased proliferation and free radical production [6]. Cytokine induced oxidative stress could potentially lead to carcinogenesis.

We hypothesized that decreased DNA damage repair is an important pathologic mechanisms in the obesity-postmenopausal BC association, and that polymorphisms in nucleotide excision repair (NER), mismatch repair (MMR) and base excision repair (BER) may modify this association. Given oxidatively induced DNA damage is repaired primarily by the BER pathway, potential modification of the obesity-postmenopausal BC association by polymorphisms in the oxidative stress pathway were also of interest. We posit that genotypes related to reduced antioxidant enzyme expression, detoxification of oxidized 
molecules, or DNA repair capacity may work in synergy with obesity to enhance the risk of postmenopausal BC. This study reports on potential interactions between body size and polymorphisms in genes related to DNA repair (ERCC1, MGMT, MLH1, MSH2, MSH3, $O G G 1, X P A, X P C, X P D, X P F, X P G$ and $X R C C 1)$ and genes involved in oxidative stress (CAT, COMT, GPX, GSTA1, GSTM1, GSTP1, GSTT1 and MPO) with respect to the risk of developing BC. Few studies have assessed this hypothesis [7-9], and only one [9] focused on interactions among postmenopausal women, where we hypothesize that modification will be most relevant [10].

\section{Materials and Methods}

We used existing genetic and questionnaire data from the case-control component of the Long Island Breast Cancer Study Project (LIBCSP), a population-based study. Details of the parent study have been reported previously [11]. Institutional Review Board approval was obtained by all participating institutions.

\section{Study population}

LIBCSP study participants were drawn from English-speaking female residents of Nassau and Suffolk counties, Long Island, New York. LIBCSP case women were aged 20-98 years and newly diagnosed with a first primary in-situ or invasive BC between August 1, 1996 and July 31, 1997. Case women were identified through daily or weekly contact with local hospital pathology departments. Population-based controls, without a personal history of $\mathrm{BC}$, were identified from among residents of the same two Long Island counties using random digit dialing for women under age 65 and Health Care Finance Administration rosters for women ages 65 and older. LIBCSP controls were frequency matched to the expected age distribution of case women by 5 -year age groups. Distributions by race were similar for cases and controls ( $94 \%$ white, $4 \%$ black, and $2 \%$ other), and are consistent with the resident populations for these counties [11].

Written informed consent was obtained from all participants prior to the study interview, Interviews were completed within about 3 months of diagnosis (reference date) for $82.1 \%$ $(\mathrm{N}=1508)$ of eligible cases and within $5 \frac{1}{2}$ months of identification (reference date) for $62.8 \%(\mathrm{~N}=1556)$ of controls. Respondents were more likely to be older (median age $=57$ years in cases and 56 years in controls), postmenopausal (classified as participants whose last menstrual period was more than 6 months prior to reference date or who had both ovaries removed before reference date), and white (93.4\% white, which reflects the underlying distribution of the source population). Among the women who completed an interview, $73.1 \%$ of cases and $73.3 \%$ of controls donated a blood sample. Among blood donors, genotyping was unavailable for $4.4 \%$ of cases and $3.4 \%$ of controls primarily due to insufficient DNA quantity. After excluding participants without body size data, our final sample of postmenopausal women includes 990 cases and 970 controls. Inconsistencies in sample size by gene polymorphism are due to varying genotyping success rates. 


\section{Single Nucleotide Polymorphism (SNP) Selection and Genotyping}

We selected 20 polymorphisms representing 12 genes in BER, NER and MMR pathways to assess interactions with obesity: ERCC1 (rs3212986), MGMT (rs12917, rs2308321 and rs2308327), MLHI (rs1799977and rs2286940), MSH2 (rs2303428, rs3732182 and rs4583514), MSH3 (rs1650663), OGG1 (rs1052113), XPA (rs1800975), XPC (rs2228000 and rs2228001), XPD (rs1799793 and rs13181), XPF (rs1800067), XPG (rs17655), XRCC1 (rs1799782 and rs25487). In addition, we identified 9 SNPs from 8 genes in the oxidative stress pathway to assess interactions with body size: COMT (rs4680 and rs737865), CAT (rs1001179), GPX (rs1050450), GSTA1 (rs3957356), GSTM1 (gene deletion), GSTP1 (rs1695), GSTT1 (gene deletion), and MPO (rs2333227). Polymorphisms in DNA repair and oxidative stress pathways were identified through the BC literature and the SNPinfo web server [12]. The associations between all polymorphisms and $\mathrm{BC}$ risk have previously been reported in the LIBCSP study population [8, 13-23].

A non-fasting $40 \mathrm{~mL}$ blood sample was obtained from participants at time of interview and shipped at room temperature, overnight, for processing. Genomic DNA was extracted from mononuclear cells in whole blood separated by Ficoll (Sigma Chemical Co., St. Louis, Missouri). Pelleted cells were frozen at $-80^{\circ} \mathrm{C}$ until DNA isolation by standard phenol, and chloroform isoamyl alcohol extraction and RNase treatment were performed [11]. SNP genotyping was performed using several high-throughput methods, which have varied over the course of the study. The fluorescence polarization (FP) method, as described by Chen and colleague's [24], was used to genotype ERCC1, MGMT, OGG1, XPC, XPD (rs13181) and XRCC1. Taqman assays (Applied Biosystems, Foster City, CA) with 384-well plates were used to genotype $X P A, X P D$ (rs1799793), $C A T$ (rs4756146, rs2284365 and rs480575) and SNPs in MMR pathway genes. Genotyping for XPF, XPG, CAT (rs1001179), GPX, GSTA1, GSTP, and MPO was performed by using Sequenom's high-throughput matrixassisted laser desorption/ionization time-of-flight mass spectrometry, while GSTMI and GSTT1 deletions were analyzed by multiplex polymerase chain reaction by Biotechnologies (Laurel, MD), as described previously [15, 17]. Controls for genotype and two non-template controls were included on each plate. Samples that were outside the variables defined by the controls were identified as non-informative and retested. For quality control, 10\% of samples were distributed throughout the DNA samples as blinded duplicates. Laboratory personnel were blinded to case-control status, and all genotyping results were reviewed manually.

\section{Body Size and Covariate Assessment}

The interviewer-administered structured questionnaire lasted approximately 101 minutes, and was completed on average within 3 months of diagnosis for cases, and 5.5 months of study identification for controls. As part of this questionnaire participants were asked about their demographic characteristics; reproductive, menstrual, environmental, and medical histories (including family history of BC); cigarette smoking and alcohol use; use of exogenous hormones; participation in recreational physical activity, and body size. Specifically, participants self-reported height to the nearest inch and weight to the nearest pound at age 20 and 1-year prior to reference date. Body mass index (BMI, weight $\mathrm{kg} / \mathrm{height}$ $\mathrm{m}^{2}$ ) at age 20 and 1-year prior to reference date were calculated for each participant based 
on the following formula: weight (in kilograms)/height (in meters squared), and used as our measures of body size. We categorized BMI using the standard World Health Organization classifications $\left(<25.0 \mathrm{~kg} / \mathrm{m}^{2} ; 25.0-29.9 \mathrm{~kg} / \mathrm{m}^{2} ;\right.$ and $\left.\geq 30 \mathrm{~kg} / \mathrm{m}^{2}\right)$. The association between $\mathrm{BMI}$ and the risk of developing $\mathrm{BC}$ has been previously reported among all women [11]; this association among postmenopausal women only is reported here.

\section{Statistical Methods}

All analyses were conducted using SAS 9.1 (Cary, NC). Odds ratios (ORs) and corresponding 95\% confidence intervals (CI's) for the association between BMI and postmenopausal $\mathrm{BC}$ risk, as well as the joint effects of genetic variants and body size, were estimated by unconditional logistic regression [25]. SNPs' effects were assessed using a dominant genetic model (at least one variant allele vs. no variant alleles) due to sparse data among women with the homozygous variant genotype. Among women with complete genotype data we conducted DNA repair and oxidative stress pathway-based analysis by combining pathway-specific genotypes to estimate the association between BMI and postmenopausal breast cancer risk within strata of low, intermediate and high number of variant alleles as described by [26]. The cutoffs for low, intermediate and high number of variant alleles were $0-7,8-13$, and $\geq 14$ for the DNA repair pathway and $0-4,5-8$, and $\geq 9$ for the oxidative stress pathway.

We identified potential confounders based on the analysis of causal diagrams [27]. For DNA repair and oxidative stress variants potential confounders included first degree family history of BC (yes/no), race (categorical), and religion (categorical). For body size, potential covariates included education (categorical), family history of BC (yes/no), history of benign breast disease (yes/no), income (categorical), lactation history (ever/never), use of oral contraceptives (ever/never), parity (categorical), recreational physical activity (ever/never) and smoking history (never, current, former). Confounders were included in the final model if their inclusion changed the exposure estimate by greater than $10 \%$ [28]. None of the covariates met our criterion. Final models were therefore adjusted only for 5-year age group and departures from the multiplicative null were assessed using the likelihood ratio test, comparing a model with and without the interaction term [29, 30].

\section{Results}

\section{BMI and Postmenopausal BC}

In the LIBCSP, among women who were overweight (BMI between $25-29.5 \mathrm{~kg} / \mathrm{m}^{2}$ ), the OR $(95 \% \mathrm{CI})$ for postmenopausal BC was $1.24(1.00,1.52)$. For women classified as obese (BMI $\left.\geq 30 \mathrm{~kg} / \mathrm{m}^{2}\right)$, the corresponding OR $(95 \% \mathrm{CI})$ was $1.36(1.09,1.71)$ (Table 1).

\section{Polymorphisms and Postmenopausal BC}

As previously described [8, 13-23], effect estimates for the associations between SNPspecific genes in the DNA repair and oxidative stress pathways and postmenopausal BC risk were largely null. 


\section{DNA Repair-BMI Interactions and Postmenopausal BC}

In the DNA repair pathway, consistent with our a priori hypotheses, we found several multiplicative interactions ( $\mathrm{p} \leq 0.05$ ) between body size and gene polymorphisms including: MGMT (rs12917), MSH2 (rs3732182 and rs4583514), MSH3 (rs1650663), XPG (rs17655), and XRCC1 (rs25487) (Table 2). Overall, we observed substantial increases in BC risk among obese women who harbored at least one minor allele while associations among obese women homozygous for the major allele were less in magnitude. For example, postmenopausal women who were heterozygous or homozygous for the minor $\mathrm{C}$ allele in MSH3 (rs1650663) and classified as obese 1-year prior to reference date experienced a greater than two-fold increase in $\mathrm{BC}$ risk [2.04 $(1.37,3.05)]$. In addition, overweight variant allele carriers were also at elevated BC risk $[1.55(1.07,2.25)]$ relative to women with BMI $<25 \mathrm{~kg} / \mathrm{m}^{2}$. In contrast, the effect of body size among women homozygous for the major allele was less pronounced; the corresponding ORs $(95 \%$ CIs) were $0.99(0.69,1.43)$ and $1.26(0.85,1.89)$, for overweight and obese women, respectively. Similar patterns of association were observed for $M G M T, M S H 2, X P G$ and $X R C C 1$. When we assessed the association between BMI and postmenopausal breast cancer risk within strata of low, intermediate and high number of variant alleles we found no interactions $(p<0.05$, data not shown).

\section{Oxidative Stress-BMI Interactions and Postmenopausal BC}

Significant multiplicative interactions ( $\leq 0.05$ ) were observed between body size and two gene polymorphisms in the oxidative stress pathway, namely GSTT1 and MPO (Table 3). The effect modification noted for MPO (rs2333227) was consistent with our a priori hypotheses, whereas the interaction finding for GSTT1 (gene deletion) was not. For example, we observed an $84 \%$ increased risk for carrying any $M P O$ variant among women classified as overweight $[1.84(1.21,2.78)]$ and a greater than two-fold risk among women classified as obese $[2.13(1.35,3.36)]$ relative to women with BMI $<25 \mathrm{~kg} / \mathrm{m}^{2}$ (p for multiplicative interaction $=0.024)$. In contrast, the pattern among women homozygous for the major allele, was less pronounced; for overweight participants the common $M P O$ genotype (CC) was associated with a very modest $5 \%$ increased risk $[1.05(0.76,1.46)]$ while among obese women the OR was only increased by $33 \%[1.33(0.93,1.89)]$ relative to women with BMI $<25 \mathrm{~kg} / \mathrm{m}^{2}$. We found no interactions $(p<0.05)$ between BMI and postmenopausal breast cancer risk within strata of low, intermediate and high number of variant alleles (data not shown).

Upon adjusting for multiple comparisons none of our associations were significant at the 0.001 significance level.

\section{Discussion}

In this population-based study, we observed a significant 24 to $36 \%$ increase in the risk of postmenopausal $\mathrm{BC}$ in relation to overweight and obesity. However, our results suggest that genotypes in DNA repair and oxidative stress pathways modify this association. Obese women with a BMI $\geq 30 \mathrm{~kg} / \mathrm{m} 2$ who carried at least one minor allele in MGMT, MSH2 (rs3732182 and rs4583514), MSH3, XPG, XRCC1 or MPO experienced significant 
increases in postmenopausal $\mathrm{BC}$ risk (excess risk ranging from $79 \%$ to greater than 2 -fold) while obese women without the variant allele experienced only modest increases (excess risk between $17 \%$ and $37 \%$ ). Our findings suggest that postmenopausal obesity could be particularly deleterious in the presence of specific, biologically plausible DNA repair or oxidative stress genotypes.

The positive association between elevated BMI (e.g. $>25 \mathrm{~kg} / \mathrm{m} 2$ ) and postmenopausal BC risk is well-documented [10]. In a 2008 review, Pichard and colleagues report risk ratios ranging from 1.26 to 2.52, which are consistent with our findings [31]. Elevated levels of circulating estrogens are proposed to underlie this positive association and are thought to result from aromatase mediated conversion of androgens to estradiol in peripheral adipose tissue, reductions in sex hormone-binding globin, and obesity related hyperinsulemia [3, 4].

However, the underlying mechanisms for the BMI-BC association are complex and remain unclear [32]. In addition to circulating estrogens, obesity may influence postmenopausal BC risk through an inflammatory pathway [5]. Adiposity is associated with a state of chronic inflammation and produces a pro-inflammatory oxidative environment [33, 34]. In this environment, adipocytes express highs levels of pro-inflammatory cytokines including tumor necrosis factor alpha (TNF- $\alpha$ ) and interleukin-6 (IL-6), and decreased antiinflammatory markers, such as adiponectin $[35,36]$. Chronic inflammation is likely to lead to changes in the cellular microenvironment, increased proliferation and oxidative stress [6]. Cytokine induced free radical production can cause damage to DNA, and if unrepaired may lead to deregulated normal cell development increasing the propensity for breast malignancy [37]. We therefore hypothesized that both decreased DNA damage repair and increased oxidative stress are important pathologic mechanisms in the obesity-BC association and may be modified by polymorphisms in these pathways.

Few studies have assessed interactions between obesity and DNA repair polymorphisms, particularly among postmenopausal women, where the obesity-BC association is most relevant [10]. Investigators from a 2005 hospital-based case-control study conducted in Korea [7] reported a borderline significant interaction between a single DNA repair SNP in ERCC4 and BMI, although stratified estimates were not provided. Women with BMI $\geq 25$ $\mathrm{kg} / \mathrm{m} 2$ and who carried the variant $C$ allele were at a 1.7 -fold $(0.96,2.93)$ increased risk of $\mathrm{BC}$ risk compared to women with $\mathrm{BMI}<25 \mathrm{~kg} / \mathrm{m} 2$ and who were homozygous for the $\mathrm{G}$ allele. Another investigation, conducted using our own LIBCSP study population [8], showed increased ORs for BC among women with BMI $\geq 25 \mathrm{~kg} / \mathrm{m} 2$ who also harbored the variant $\mathrm{G}$ allele for two SNPs in OGG1 [7143A/G: 1.47(1.10, 1.96) and 11657A/G: $1.41(1.05,1.88)]$, relative to women with $\mathrm{BMI}<25 \mathrm{~kg} / \mathrm{m} 2$ and the common genotype. This study showed no evidence of interaction between BMI and the Ser326Cys polymorphism, however, modification was importantly not assessed within strata of menopausal status.

Similarly, there are few population-based studies that have considered potential interaction between body size and oxidative stress gene polymorphisms. For example, in the LIBCSP, we previously considered interactions between body size and genetic polymorphisms in MnSOD, but found no evidence to support interaction on the multiplicative scale [9]. Some studies have estimated associations between urinary F2-isoprostanes (IsoP), secondary end 
products of lipid peroxidation, and $\mathrm{BC}$ risk examining potential modification by BMI. In the LIBCSP we found similar associations among women in the highest quartile of 15-F2t-IsoP levels compared with the lowest quartile irrespective of body size (BMI $<25$ and BMI $\geq 25)$ [38]. In contrast, findings from the Shanghai Women's Health Study indicate the association between 15-F2t-IsoP and BC may be modified by BMI [39]. While 15-F2t-IsoP and its metabolite 15-F2t-IsoPM were inversely associated with BC risk among women with a $\mathrm{BMI}<25$, the association was positive among women with a BMI $\geq 25$. The magnitude of these associations became stronger among women with a higher BMI, although the estimates were imprecise. These data suggest that although 15-F2t-IsoP is the most frequently used biomarker of oxidative stress, it may not accurately reflect interactions with obesity.

Related findings from other studies, in conjunction with our own, also lend support to our hypothesis that obesity may differentially impact women with certain DNA repair or oxidative stress genotypes. For example, in human lymphocytes, the MGMT (Leu84Phe) polymorphism results in suboptimal repair of genetic damage [40]. Women who carry the variant $\mathrm{T}$ allele may therefore not be able to effectively repair damage caused by obesity mediated reactive oxygen species resulting in augmented $\mathrm{BC}$ risk. While these findings are suggestive of enhanced risk among obese women with deficient antioxidant or repair capacity, the functional significance of many of the polymorphisms evaluated remains to be resolved [41, 42]. Our findings should therefore be interpreted with caution.

Our study has potential limitations, which should be considered during the interpretation of our results. In the LIBCSP, blood donation varied by both age and race [11]. Although genotype may be associated with race, given the small number of non-white women included in the study, potential racial variation in blood donation is likely negligible. We were unable to explore potential variation by BC subtype given our limited study power and low proportion of women with HER2-tumors. We assessed BMI 1-year prior to reference date to account for any changes in weight that may occur with chemotherapy initiation. However, this time point may not represent the etiologically relevant time period for breast carcinogenesis. It is also plausible that there was differential recall of body size with respect to case status. However, neither cases nor controls were aware of their genotype at the time of interview and it is unlikely that systematic differences in recall persist across strata of genotype [23]. We therefore do not anticipate that any misclassification of body size would bias our interaction parameter estimates. While the number of tests may have led to chance findings, it is unlikely that we would find evidence of interaction for more than $25 \%$ of the polymorphisms assessed based on chance alone. Although we recognize that correction for multiple comparisons is important and have included Bonferroni adjusted results, this correction may be unduly conservative. Our study hypotheses were based on strong biologic rationale and we employed a targeted candidate-gene approach. Given this is one of the first studies to assess potential modification of the BMI-postmenopausal BC association by genotypes in these two pathways, we were primarily interested in estimating effects and corresponding CIs without adjusting for multiple comparisons. These data may provide rational for future investigation and replication. Finally, the pathways selected for investigation represent a small proportion of a number of proposed mechanisms through which obesity may influence postmenopausal BC risk [43]. Other pathways (e.g., sex- 
steroid) were not considered and we were unable to simultaneously examine multiple pathways using higher level modeling (e.g. hierarchical) due to limited power. These potential limitations should be explored in future investigations.

\section{Conclusions}

This study found evidence of interaction between BMI and six variants in DNA repair and two SNPs in the oxidative stress, respectively. The observed multiplicative interaction supports our biologically plausible hypothesis that obesity may be associated with a proinflammatory oxidative environment, and that insufficient antioxidant capacity or DNA repair could result in damage to cellular constituents (e.g., DNA) and enhanced postmenopausal BC risk. While we detected interactions across multiple gene polymorphisms, the limited functional data in these SNPs limits our ability to make strong conclusions. Replication of our results, in addition to new mechanistic data, will further enhance our understanding and negate any suggestions of chance discovery.

\section{Acknowledgments}

This work was supported in part by grants from the Department of Defense (Grant no. BC093608), the National Cancer Institute and the National Institutes of Environmental Health and Sciences (Grant nos. UO1CA/ES66572, P30ES009089, P30ES10126, P50CA058223, R25CA057726).

\section{Abbreviations}

$\begin{array}{ll}\text { BC } & \text { breast cancer } \\ \text { BER } & \text { base excision repair } \\ \text { BMI } & \text { body mass index } \\ \text { CI } & \text { confidence interval } \\ \text { FP } & \text { fluorescence polarization } \\ \text { ICR } & \text { interaction contrast ratio } \\ \text { IL-6 } & \text { interleukin-6 } \\ \text { IsoP } & \text { isoprostanes } \\ \text { LIBCSP } & \text { Long Island breast cancer study project } \\ \text { MMR } & \text { mismatch repair } \\ \text { NER } & \text { nucleotide excision repair } \\ \text { OR } & \text { odds ratio } \\ \text { SHBG } & \text { sex hormone binding globulin } \\ \text { SNP } & \text { single nucleotide polymorphism } \\ \text { TNF-a } & \text { tumor necrosis factor-a }\end{array}$




\section{References}

1. Rose DP, Haffner SM, Baillargeon J. Adiposity, the metabolic syndrome, and breast cancer in african-american and white american women. Endocr Rev. 2007 Dec; 28(7):763-77. [PubMed: 17981890]

2. Ogden CL, Carroll MD, Kit BK, Flegal KM. Prevalence of obesity in the United States, 2009-2010. NCHS Data Brief. 2012 Jan.(82):1-8.

3. Muti P. The role of endogenous hormones in the etiology and prevention of breast cancer: The epidemiological evidence. Ann N Y Acad Sci. 2004 Dec.1028:273-82. [PubMed: 15650252]

4. Key TJ, Allen NE, Verkasalo PK, Banks E. Energy balance and cancer: The role of sex hormones. Proc Nutr Soc. 2001 Feb; 60(1):81-9. [PubMed: 11310427]

5. Mena S, Ortega A, Estrela JM. Oxidative stress in environmental-induced carcinogenesis. Mutat Res. 2009 Mar 31; 674(1-2):36-44. [PubMed: 18977455]

6. Coussens LM, Werb Z. Inflammation and cancer. Nature. 2002 Dec 19-26; 420(6917):860-7. [PubMed: 12490959]

7. Lee SA, Lee KM, Park WY, Kim B, Nam J, Yoo KY, Noh DY, Ahn SH, Hirvonen A, Kang D. Obesity and genetic polymorphism of ERCC2 and ERCC4 as modifiers of risk of breast cancer. Exp Mol Med. 2005 Apr 30; 37(2):86-90. [PubMed: 15886521]

8. Rossner P, Terry MB, Gammon MD, Zhang FF, Teitelbaum SL, Eng SM, Sagiv SK, Gaudet MM, Neugut AI, Santella RM. OGG1 polymorphisms and breast cancer risk. Cancer Epidemiol Biomarkers Prev. 2006 Apr; 15(4):811-5. [PubMed: 16614128]

9. Gaudet MM, Gammon MD, Santella RM, Britton JA, Teitelbaum SL, Eng SM, Terry MB, Bensen JT, Schroeder J, Olshan AF, et al. MnSOD val-9Ala genotype, pro- and anti-oxidant environmental modifiers, and breast cancer among women on Long Island, New York. Cancer Causes Control. 2005 Dec; 16(10):1225-34. [PubMed: 16215873]

10. Friedenreich CM. Review of anthropometric factors and breast cancer risk. Eur J Cancer Prev. 2001 Feb; 10(1):15-32. [PubMed: 11263588]

11. Gammon MD, Neugut AI, Santella RM, Teitelbaum SL, Britton JA, Terry MB, Eng SM, Wolff MS, Stellman SD, Kabat GC, et al. The Long Island Breast Cancer Study Project: Description of a multi-institutional collaboration to identify environmental risk factors for breast cancer. Breast Cancer Res Treat. 2002 Jun; 74(3):235-54. [PubMed: 12206514]

12. Zongli X, Taylor J. SNPinfo: Integrating GWAS and Candidate Gene Information into Functional SNP Selection for Genetic Association Studies. Nucleic Acids Re. 2009 Jul; 37(Web Server issue):W600-W605.

13. Ahn J, Gammon MD, Santella RM, Gaudet MM, Britton JA, Teitelbaum SL, Terry MB, Neugut AI, Ambrosone CB. No association between glutathione peroxidase Pro198Leu polymorphism and breast cancer risk. Cancer Epidemiol Biomarkers Prev. 2005 Oct; 14(10):2459-61. [PubMed: 16214934]

14. Ahn J, Gammon MD, Santella RM, Gaudet MM, Britton JA, Teitelbaum SL, Terry MB, Neugut AI, Eng SM, Zhang Y, et al. Effects of glutathione S-transferase A1 (GSTA1) genotype and potential modifiers on breast cancer risk. Carcinogenesis. 2006 Sep; 27(9):1876-82. [PubMed: 16624829]

15. Ahn J, Gammon MD, Santella RM, Gaudet MM, Britton JA, Teitelbaum SL, Terry MB, Neugut AI, Josephy PD, Ambrosone CB. Myeloperoxidase genotype, fruit and vegetable consumption, and breast cancer risk. Cancer Res. 2004 Oct 15; 64(20):7634-9. [PubMed: 15492293]

16. Ahn J, Gammon MD, Santella RM, Gaudet MM, Britton JA, Teitelbaum SL, Terry MB, Nowell S, David W, Garza C, et al. Associations between breast cancer risk and the catalase genotype, fruit and vegetable consumption, and supplement use. Am J Epidemiol. 2005 Nov 15; 162(10):943-52. [PubMed: 16192345]

17. Steck SE, Gaudet MM, Britton JA, Teitelbaum SL, Terry MB, Neugut AI, Santella RM, Gammon MD. Interactions among GSTM1, GSTT1 and GSTP1 polymorphisms, cruciferous vegetable intake and breast cancer risk. Carcinogenesis. 2007 Sep; 28(9):1954-9. [PubMed: 17693660]

18. Crew KD, Gammon MD, Terry MB, Zhang FF, Zablotska LB, Agrawal M, Shen J, Long CM, Eng SM, Sagiv SK, et al. Polymorphisms in nucleotide excision repair genes, polycyclic aromatic 
hydrocarbon-DNA adducts, and breast cancer risk. Cancer Epidemiol Biomarkers Prev. 2007 Oct; 16(10):2033-41. [PubMed: 17932351]

19. Shen J, Gammon MD, Terry MB, Teitelbaum SL, Eng SM, Neugut AI, Santella RM. Xeroderma pigmentosum complementation group $\mathrm{C}$ genotypes/diplotypes play no independent or interaction role with polycyclic aromatic hydrocarbons-DNA adducts for breast cancer risk. Eur J Cancer. 2008 Mar; 44(5):710-7. [PubMed: 18053706]

20. Shen J, Gammon MD, Terry MB, Wang L, Wang Q, Zhang F, Teitelbaum SL, Eng SM, Sagiv SK, Gaudet MM, et al. Polymorphisms in XRCC1 modify the association between polycyclic aromatic hydrocarbon-DNA adducts, cigarette smoking, dietary antioxidants, and breast cancer risk. Cancer Epidemiol Biomarkers Prev. 2005 Feb; 14(2):336-42. [PubMed: 15734955]

21. Shen J, Terry MB, Gammon MD, Gaudet MM, Teitelbaum SL, Eng SM, Sagiv SK, Neugut AI, Santella RM. MGMT genotype modulates the associations between cigarette smoking, dietary antioxidants and breast cancer risk. Carcinogenesis. 2005 Dec; 26(12):2131-7. [PubMed: 16014702]

22. McCullough LE, Santella RM, Cleveland RJ, Millikan RC, Olshan AF, North KE, Bradshaw PT, Eng SM, Terry MB, Shen J, et al. Polymorphisms in DNA repair genes, recreational physical activity and breast cancer risk. Int J Cancer. 2013 Feb 1; 134(3):654-63. [PubMed: 23852586]

23. Terry MB, Gammon MD, Zhang FF, Eng SM, Sagiv SK, Paykin AB, Wang Q, Hayes S, Teitelbaum SL, Neugut AI, et al. Polymorphism in the DNA repair gene XPD, polycyclic aromatic hydrocarbon-DNA adducts, cigarette smoking, and breast cancer risk. Cancer Epidemiol Biomarkers Prev. 2004 Dec; 13(12):2053-8. [PubMed: 15598760]

24. Chen X, Levine L, Kwok PY. Fluorescence polarization in homogeneous nucleic acid analysis. Genome Res. 1999 May; 9(5):492-8. [PubMed: 10330129]

25. Kleinbaum, DG.; Klein, M. Logistic regression; a self-learning text. 2. New York: Springer; 2002.

26. Mohrenweiser HW, Wilson DM III, Jones IM. Challenges and complexities in estimating boththe functional impact and the disease risk associated with the extensive genetic variation in human DNA repair genes. Mutat Res. 2003; 526:93-125. [PubMed: 12714187]

27. Greenland S, Brumback B. An overview of relations among causal modelling methods. Int J Epidemiol. 2002 Oct; 31(5):1030-7. [PubMed: 12435780]

28. Greenland S. Modeling and variable selection in epidemiologic analysis. Am J Public Health. 1989 Mar; 79(3):340-9. [PubMed: 2916724]

29. Breslow NE, Day NE. Statistical methods in cancer research. volume I - the analysis of casecontrol studies. IARC Sci Publ. 1980; (32):5-338. [PubMed: 7216345]

30. Assmann SF, Hosmer DW, Lemeshow S, Mundt KA. Confidence intervals for measures of interaction. Epidemiology. 1996 May; 7(3):286-90. [PubMed: 8728443]

31. Pichard C, Plu-Bureau G, Neves-E Castro M, Gompel A. Insulin resistance, obesity and breast cancer risk. Maturitas. 2008 May 20; 60(1):19-30. [PubMed: 18485631]

32. Pischon T, Nothlings U, Boeing H. Obesity and cancer. Proc Nutr Soc. 2008 May; 67(2):128-45. [PubMed: 18412987]

33. Esposito K, Nappo F, Marfella R, Giugliano G, Giugliano F, Ciotola M, Quagliaro L, Ceriello A, Giugliano D. Inflammatory cytokine concentrations are acutely increased by hyperglycemia in humans: Role of oxidative stress. Circulation. 2002 Oct 15; 106(16):2067-72. [PubMed: 12379575]

34. Mohanty P, Hamouda W, Garg R, Aljada A, Ghanim H, Dandona P. Glucose challenge stimulates reactive oxygen species (ROS) generation by leucocytes. J Clin Endocrinol Metab. 2000 Aug; 85(8):2970-3. [PubMed: 10946914]

35. Hotamisligil GS, Shargill NS, Spiegelman BM. Adipose expression of tumor necrosis factor-alpha: Direct role in obesity-linked insulin resistance. Science. 1993 Jan 1; 259(5091):87-91. [PubMed: 7678183]

36. Arita Y, Kihara S, Ouchi N, Takahashi M, Maeda K, Miyagawa J, Hotta K, Shimomura I, Nakamura T, Miyaoka K, et al. Paradoxical decrease of an adipose-specific protein, adiponectin, in obesity. Biochem Biophys Res Commun. 1999 Apr 2; 257(1):79-83. [PubMed: 10092513]

37. Berquist BR, Wilson DM 3rd. Pathways for repairing and tolerating the spectrum of oxidative DNA lesions. Cancer Lett. 2012 Dec 31; 327(1-2):61-72. [PubMed: 22353689] 
38. Rossner P Jr, Gammon MD, Terry MB, Agrawal M, Zhang FF, Teitelbaum SL, Eng SM, Gaudet MM, Neugut AI, Santella RM. Relationship between urinary 15-F2t-isoprostane and 8oxodeoxyguanosine levels and breast cancer risk. Cancer Epidemiol Biomarkers Prev. 2006 Apr; 15(4):639-44. [PubMed: 16614103]

39. Dai Q, Gao YT, Shu XO, Yang G, Milne G, Cai Q, Wen W, Rothman N, Cai H, Li H, et al. Oxidative stress, obesity, and breast cancer risk: Results from the Shanghai Women's Health Study. J Clin Oncol. 2009 May 20; 27(15):2482-8. [PubMed: 19380446]

40. Molina E, Perez-Morales R, Rubio J, Petrosyan P, Cadena LH, Arlt VM, Phillips DH, Gonsebatt ME. The GSTM1null (deletion) and MGMT84 rs12917 (Phe/Phe) haplotype are associated with bulky DNA adduct levels in human leukocytes. Mutat Res. 2013 Sep 29.

41. Vani M, Reddy GP, Reddy GR, Thyagaraju K, Reddanna P. Glutathione-S-transferase, superoxide dismutase, xanthine oxidase, catalase, glutathione peroxidase and lipid peroxidation in the liver of exercised rats. Biochem Int. 1990; 21(1):17-26. [PubMed: 2386536]

42. Evelo CT, Palmen NG, Artur Y, Janssen GM. Changes in blood glutathione concentrations, and in erythrocyte glutathione reductase and glutathione $\mathrm{S}$-transferase activity after running training and after participation in contests. Eur J Appl Physiol Occup Physiol. 1992; 64(4):354-8. [PubMed: 1592062]

43. Osorio-Costa F, Rocha GZ, Dias MM, Carvalheira JB. Epidemiological and molecular mechanisms aspects linking obesity and cancer. Arq Bras Endocrinol Metabol. 2009 Mar; 53(2): 213-26. [PubMed: 19466214] 


\section{TABLE 1}

Age-adjusted odds ratios (OR) and 95\% confidence intervals (CI) for the association between body mass index (BMI) and postmenopausal breast cancer risk, Long Island Breast Cancer Study Project (1996-1997).

\begin{tabular}{llll}
\hline \multirow{2}{*}{$\mathbf{B M I} \boldsymbol{c}$} & $\mathbf{C a}^{\boldsymbol{a}} / \mathbf{C o} \boldsymbol{b}$ & $\mathbf{O R}$ & $\mathbf{9 5 \%} \mathbf{C I}$ \\
\cline { 2 - 4 }$<25 \mathrm{~kg} / \mathrm{m} 2$ & $386 / 439$ & 1.00 & Reference \\
$25-29.9 \mathrm{~kg} / \mathrm{m} 2$ & $340 / 309$ & 1.24 & $(1.00-1.52)$ \\
$230 \mathrm{~kg} / \mathrm{m} 2$ & $264 / 222$ & 1.36 & $(1.09-1.71)$ \\
\hline${ }^{a}$ Cases; & & & \\
${ }^{b}$ Controls; & & & \\
${ }^{c}{ }_{\text {1-year prior to reference date }}$ & &
\end{tabular}




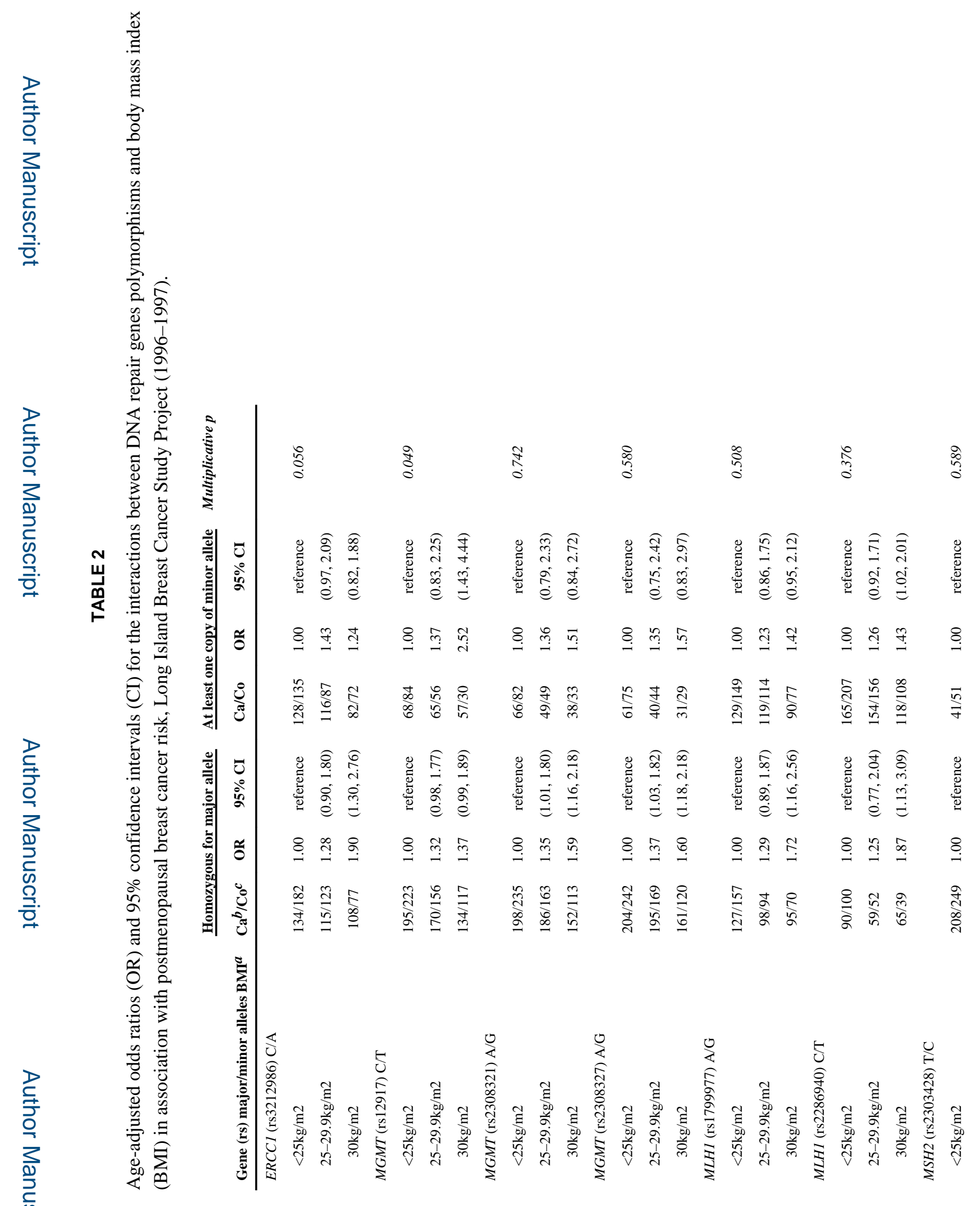




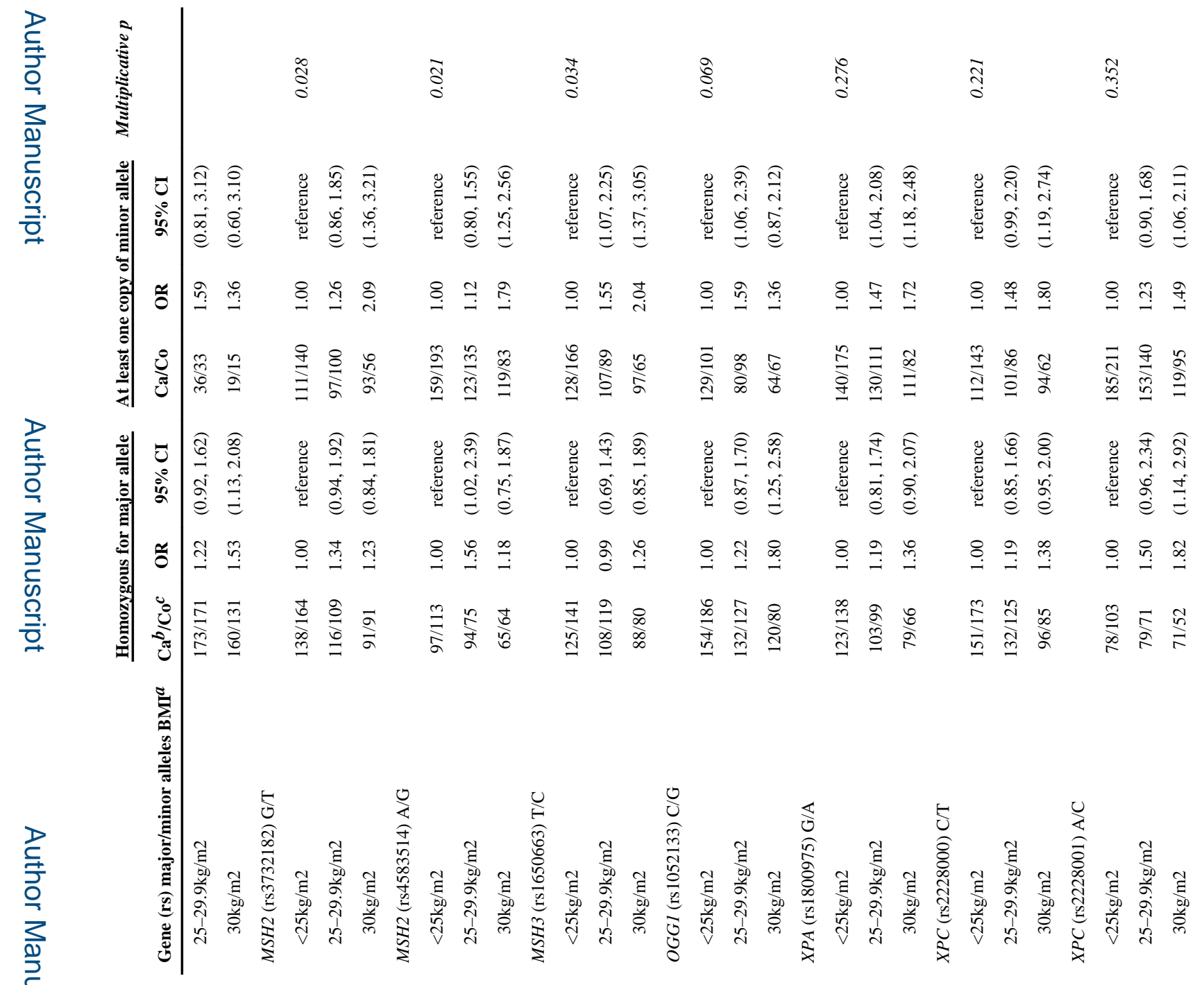




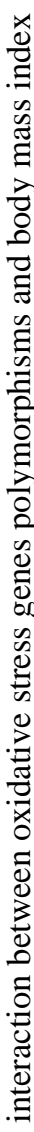

氖

已)

@

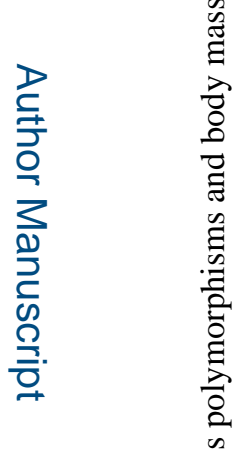

要

品突

กิ

$\infty$

के

రై

$\stackrel{m}{2}$

ลิ

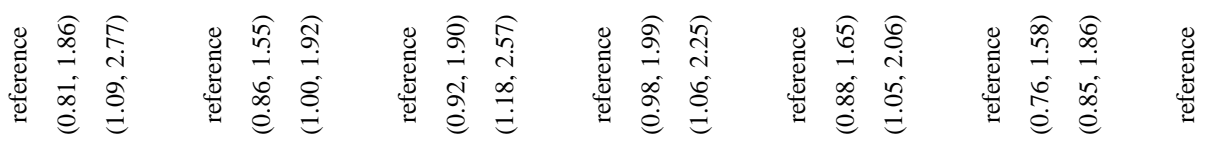

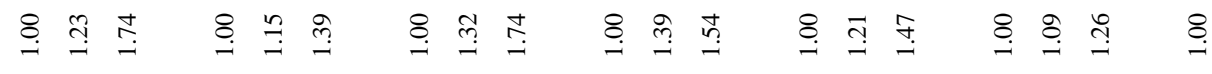

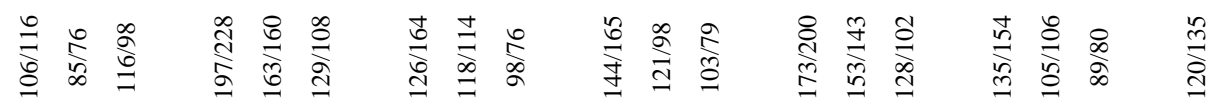

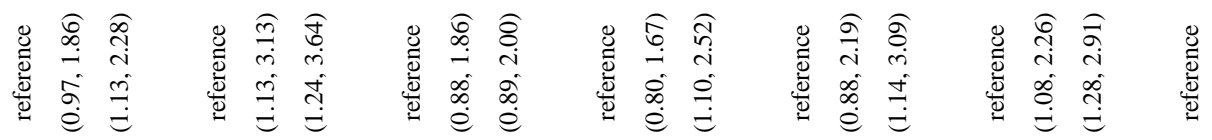

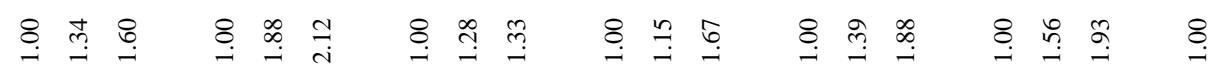

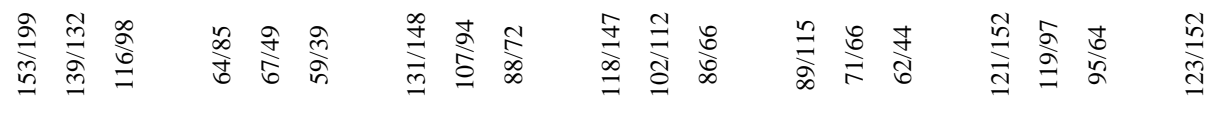

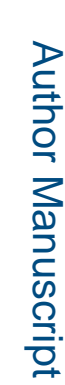

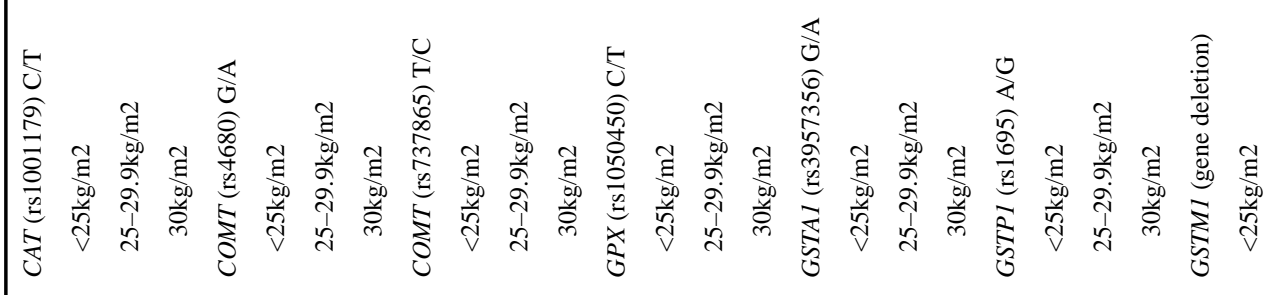

Ann Epidemiol. Author manuscript; available in PMC 2016 April 01. 


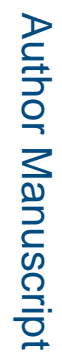

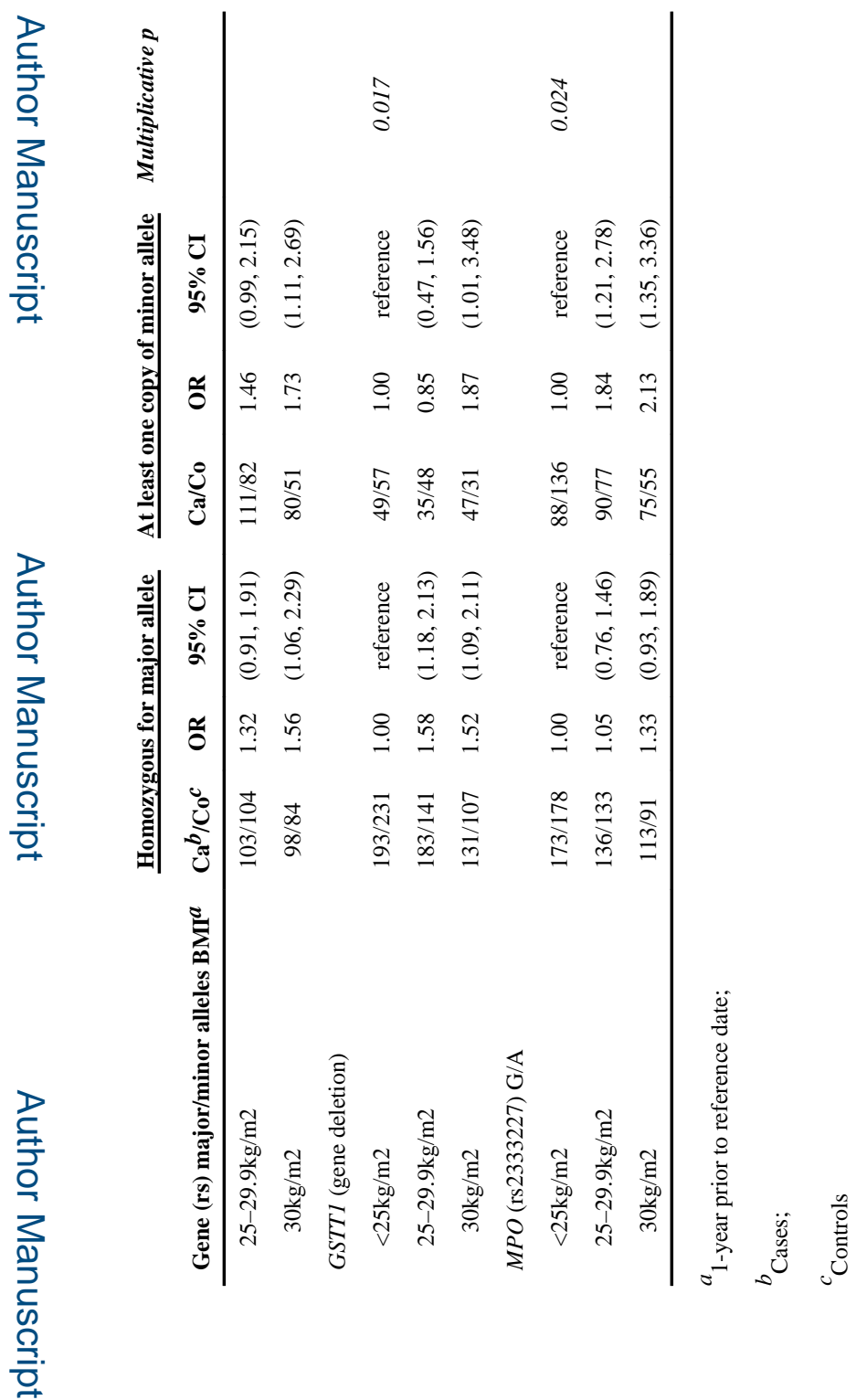

Ann Epidemiol. Author manuscript; available in PMC 2016 April 01 